\title{
Remoção de compostos fenólicos em reatores anaeróbios de leito fixo com diferentes materiais suporte
}

\author{
Fátima R. L. Fia ${ }^{1}$, Antonio T. de Matos ${ }^{2}$, Alisson C. Borges ${ }^{2}$, Débora A. Moreira ${ }^{2}$, Ronaldo Fia $^{1} \&$ Valdeir Eustáquio Júnior ${ }^{2}$
}

\section{RESUMO}

O bjetivou-se, com a realização deste estudo, efetuar a avaliação operacional de três reatores anaeróbios de leito fixo e com escoamento ascendente, contendo biomassa imobilizada na remoção de compostos fenólicos presentes na água residuária do processamento dos frutos do cafeeiro (ARC). O s suportes utilizados na imobilização da biomassa foram: escória de alto-forno espuma de poliuretano e brita. Os reatores, confeccionados em PVC e com volume total de 139,5 L, foram alimentados com concentrações crescentes de compostos fenólicos (13, 19,7 e 42,7 $\left.\mathrm{mg} \mathrm{L}^{-1}\right)$, sendo que 0 tempo de detenção hidráulica (TDH) foi mantido em torno de 1,3 dias. No final de cada condição avaliada foram coletadas amostras de ARC, ao longo da altura dos reatores, para estudo cinético. A rápida aclimatação da biomassa aderida à escória resultou em uma eficiência maior de remoção de compostos fenólicos no período de partida bem como no melhor desempenho deste reator quanto à remoção desses compostos ao longo do período de experimentação. $0 \mathrm{~s}$ resultados indicaram que a escória de alto-forno apresentou maior potencial de utilização como material suporte de reatores anaeróbios, visando à remoção de compostos fenólicos da ARC.

Palavras-chave: digestão anaeróbia, fenol, café, efluente agroindustrial

\section{Removal of the phenolic compounds in fixed bed anaerobic reactors with different support material}

\begin{abstract}
The operation of three fixed-bed anaerobic reactors with upflow and containing immobilized biomass were evaluated as regards to the removal of phenolic compounds found in the wastewater from coffee bean processing (RWC). The supports used in immobilization of the biomass were blast-furnace cinders, polyurethane foam and crushed stone. The PVC-made reactors with $139.5 \mathrm{~L}$ total volume were fed with increasing concentrations (13, 19.7 and $42.7 \mathrm{mg} \mathrm{L}^{-1}$ ) of phenolic compounds, and the hydraulic residence time (HRT) was maintained constant (around 1.3 days). At the end of each evaluated condition, samples were collected from the RWC along the height of the reactor for kinetic studies. Rapid acclimation of biomass attached to the blast-furnace cinders resulted in increased efficiency of removal of phenolic compounds in start-up, and the best performance of this reactor regarding the removal of these compounds over the period of the experiment. According to the results, the blast furnace cinders showed higher potential for use as supporting material of anaerobic reactors, when the objective is the removal of the phenolic compounds from RWC.
\end{abstract}

Key words: anaerobic digestion, phenol, coffee, agroindustrial effluent

1 DEG/UFLA. CP 3037, Campus da UFLA. CEP 37200-000. Lavras, M G. Fone: (35) 3829-1481. E-mail: fatimarlf@deg.ufla.br; ronaldofia@deg.ufla.br 2 DEA/UFV. Av. PH Rolfs, s/n, Campus da UFV. CEP 36570-000. Viçosa, MG. Fone: (31) 3899-2729. E-mail: atmatos@ufv.br; borges@ufv.br; deboraastoni@yahoo.com.br; vejunior@gmail.com 


\section{INTRODUÇÃO}

Nas últimas décadas, maior atenção tem sido dada à presença de fenóis e seus derivados no ambiente devido às elevadas concentrações encontradas em despejos de diferentes origens, sua natureza tóxica e seus efeitos adversos em corpos hídricos receptores (Sarkar \& Acharya, 2006). Os fenóis são solúveis em água e altamente móveis e, como consequência, podem atingir, com rapidez, as fontes de água, causando problemas de toxicidade para espécies aquáticas, bem como gosto e odor desagradáveis em águas de abastecimento público, mesmo quando presentes em baixas concentrações ( Jiang et al., 2002).

No ambiente aquático os compostos fenólicos podem ser formados como subprodutos de reações de degradação de substâncias naturais ou estarem presentes em razão de contaminações provocadas por práticas agrícolas ou atividades industriais. Vários tipos de fenóis naturais e seus produtos condensados, como os taninos e as ligninas, podem estar presentes em diferentes tipos de resíduos agroindustriais. Como exemplos têm-se as águas residuárias do processamento da madeira para fabricação de papel e tacos (Tello, 2001); de cortiça; de curtumes, que utilizam taninos naturais; de indústrias vinícolas; do processamento do óleo de oliva (Fezzani $\&$ Cheikh, 2007) e do processamento dos frutos do cafeeiro (Luiz et al., 2004; Bruno \& Oliveira, 2008).

Veeresh et al. (2005) citaram que o conteúdo de compostos fenólicos em águas residuárias pode variar de 10 a 17.000 $\mathrm{mg} \mathrm{L}^{-1}$, sendo normalmente mais alto que o limite padrão de $0,5 \mathrm{mg} \mathrm{L}^{-1}$, estabelecido no Brasil (Brasil, 2005) para o seu lançamento no meio aquático. Diante da necessidade cada vez maior de preservação dos recursos naturais, torna-se essencial o desenvolvimento de sistemas de tratamento que sejam satisfatórios, do ponto de vista técnico e operacional e proporcionem remoção eficiente das cargas desses poluentes das águas residuárias.

As tecnologias para o tratamento de águas residuárias que contêm fenol incluem cloração, ozonização, adsorção, extração com solvente, processos com membranas, coagulação, floculação e tratamento biológico; no entanto, métodos físico-químicos demonstraram ser mais dispendiosos, além de estarem associados à formação de materiais tóxicos secundários, tais como fenóis clorados e hidrocarbonetos. Por isso, os métodos biológicos de tratamento se têm mostrado técnica e economicamente mais adequados para degradação e completa mineralização dos fenóis (Khleifat, 2006).

Segundo Bolaños et al. (2001), o fenol pode ser degradado tanto por via aeróbia como anaeróbia. Entretanto, é tóxico aos microrganismos, principalmente aos não aclimatados, mesmo em concentrações relativamente baixas, como as de $10 \mathrm{mg} \mathrm{L}^{-1}$. Entretanto, alguns compostos tóxicos e recalcitrantes podem ser completamente mineralizados ou ter sua toxicidade diminuída em sistemas de tratamento biológico, quando estes são corretamente projetados e operados evitando-se a formação de poluentes secundários (Bae et al., 1995).

A degradação de fenol a metano e gás carbônico em ambiente anaeróbio, ocorre por meio de uma série de reações em cadeia que incluem a desaromatização, acetogênese e meta- nogênese (Fang et al., 2006). A conversão de fenol para benzoato é o primeiro passo para a degradação anaeróbia desse constituinte. O benzoato é, então, desaromatizado para formar ácido carboxílico ciclohexano e, em seguida, a estrutura do anel é rompida, formando o heptanoato. O heptanoato é, então, fragmentado para formar acetato (precursor do metano). Segundo Fang et al. (2004), a conversão do fenol a benzoato aparenta ser o fator limitante no processo de degradação do fenol.

Entender o processo cinético de degradação do fenol é essencial para projetar, desenvolver e operar reatores utilizados no tratamento de águas residuárias que apresentam este composto. Com o conhecimento dos processos bioquímicos e microbiológicos pode-se descrever a taxa de utilização do fenol no processo de degradação. Além disso, a cinética do processo também engloba fatores operacionais e ambientais que afetam a taxa de remoção deste composto (Bhunia \& Ghangrekar, 2008).

Vários trabalhos têm relatado os estudos cinéticos sobre o crescimento bacteriano, principalmente no que diz respeito à aplicação da equação de Monod (Eq. 1) aos resultados de crescimento obtidos em sistemas tipo batelada (Kumaran \& Paruchuri, 1997).

$$
\mu=\mu_{\max } \frac{S}{K_{S}+S}
$$

em que:

$\mu$ - taxa de crescimento específica;

$\mu_{\max }$ - máxima taxa de crescimento específica;

$\mathrm{K}_{\mathrm{S}}$ - concentração do substrato correspondente à metade do valor de $\mu_{\max }$;

$\mathrm{S}$ - concentração do substrato.

No cálculo das constantes cinéticas, $\mu, \mu_{\max }$ e $\mathrm{K}_{\mathrm{S}}$ estão relacionadas às funções reator (Monod, 1950).

O modelo de Monod tem sido amplamente utilizado para a estimativa das constantes cinéticas do crescimento bacteriano em substratos que apresentam compostos inibitórios e não inibitórios (Kumaran \& Paruchuri, 1997); no entanto, o reconhecimento da inibição do crescimento bacteriano por substrato que contém fenol leva a uma revisão na aplicação do modelo de Monod, devendo ser preteridos modelos de crescimento que consideram o efeito inibitório desse composto. Uma das equações amplamente utilizadas neste caso é a equação de Haldane (Eq. 2).

$$
\mu=\mu_{\max } \frac{\mathrm{S}}{\mathrm{K}_{\mathrm{S}}+\mathrm{S}+\frac{\mathrm{S}^{2}}{\mathrm{~K}_{\mathrm{i}}}}
$$

donde $K_{i}$ indica a concentração do substrato acima da qual a taxa de crescimento dos microrganismos é menor que $\mu_{\max } / 2$, indicando efeito inibitório.

A taxa específica de crescimento $(\mu)$ tende a aumentar à medida que o substrato é aumentado (relação tipo Monod), porém $\mu$ também tende a diminuir devido ao efeito inibitório do substrato $(S)$ com o aumento na sua concentração. 
Várias relações cinéticas foram concebidas para representar a dependência conjunta do $\mu$ e do $S$ como substrato e como inibidor, assim como a proposta por Haldane (Eq. 2). Esta equação é semelhante à equação de Michaelis-Menten, ou a equação de Monod, com a adição de um termo $\left(K_{i}\right)$ que avalia a inibição da constante. Este termo prevê que, à medida em que $S$ aumenta, $\mu$ também aumenta para um valor máximo e, finalmente, diminui com o aumento no efeito inibitório (Bhunia \& Ghangrekar, 2008).

Assim, no presente estudo, teve-se como objetivo avaliar o desempenho de reatores anaeróbios de leito fixo e com fluxo ascendente, preenchidos com diferentes materiais suporte, na degradação de compostos fenólicos provenientes das águas residuárias do processamento dos frutos do cafeeiro.

\section{MATERIAL E MÉTODOS}

Os reatores anaeróbios de leito fixo e com escoamento ascendente foram construídos com tubos de PVC de $0,35 \mathrm{~m}$ de diâmetro, altura de $1,5 \mathrm{~m}$ e volume total de $0,1395 \mathrm{~m}^{3}$. Ao longo da altura dos reatores se instalaram amostradores para a coleta de ARC em tratamento, a fim de se determinar o perfil de degradação dos compostos fenólicos.

Utilizaram-se, como material suporte para imobilização da biomassa, matrizes de escória de alto-forno, espuma de poliuretano e brita, o que resultou nos reatores R1, R2 e R3, respectivamente. As principais características do material suporte se apresentam na Tabela 1 enquanto a composição química da escória pode ser observada na Tabela 2 .

Tabela 1. Dados obtidos das análises de caracterização dos materiais suporte

\begin{tabular}{cccc}
\hline Características & \multicolumn{3}{c}{ Material suporte } \\
\cline { 2 - 4 } & Escória & Espuma & Brita \\
Massa específica $\left(\mathrm{kg} \mathrm{m}^{-3}\right)$ & 2.480 & 23 & 2.820 \\
Volume de vazios $\left(\mathrm{m}^{3} \mathrm{~m}^{-3}\right)$ & 0,533 & 0,950 & 0,484 \\
\hline
\end{tabular}

Tabela 2. Análise química da escória de alto forno

\begin{tabular}{|c|c|c|c|c|c|c|c|c|c|}
\hline $\mathrm{SiO}_{2}$ & $\mathrm{CaO}$ & $\mathrm{MgO} \quad \mathrm{Al}_{2} \mathrm{O}_{3}$ & $\mathrm{FeO}$ & $\mathrm{MnO}$ & $\mathrm{K}_{2} \mathrm{O}$ & $\overline{\mathrm{Ti}}$ & 5 & $\mathrm{Cr}_{2} \mathrm{O}_{3}$ & $\overline{e d e}$ \\
\hline
\end{tabular}

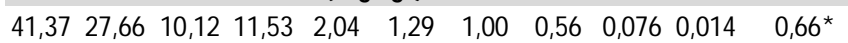

*adimensional

Usou-se, para inocular os reatores, lodo de esgoto proveniente de um reator UASB, o qual apresentou concentração média de SVT e SSV de 41.346 e $36.860 \mathrm{mg} \mathrm{L}^{-1}$, respectivamente. O material suporte, juntamente com o lodo, preparado de acordo com Zaiat et al. (1994), foi colocado em tambores de $200 \mathrm{~L}$, onde foram revirados durante uma semana, de modo a promover maior imobilização das biopartículas nos materiais suporte; subsequentemente, a escória de alto-forno, a espuma de poliuretano e a brita, foram acondicionadas nos seus respectivos reatores; em seguida, procedeu-se à "partida". Durante este período, sabidamente de maior sensibilidade na operação dos reatores, teve-se o cuidado em aplicar menores cargas orgânicas a fim de promover a aclimatação da biomassa ao novo ambiente com mínimo estresse (Tabela 3).

Tabela 3. Características operacionais dos três reatores anaeróbios de leito fixo

\begin{tabular}{|c|c|c|c|c|}
\hline \multirow{2}{*}{ Fases } & \multirow{2}{*}{ Variáveis } & \multicolumn{3}{|c|}{ Reatores } \\
\hline & & R1 & R2 & R3 \\
\hline \multirow{3}{*}{$\begin{array}{c}\text { I } \\
\text { (Partida) }\end{array}$} & $\mathrm{TDH}(\mathrm{d})$ & $1,19 \pm 0,29(39)$ & $1,07 \pm 0,27(39)$ & $1,26 \pm 0,38(39)$ \\
\hline & $\operatorname{COV}\left(\mathrm{kg} \mathrm{m}^{-3} \mathrm{~d}^{-1}\right)$ & $0,81 \pm 0,21(16)$ & $0,98 \pm 0,28(16)$ & $0,81 \pm 0,22(16)$ \\
\hline & $\mathrm{CHV}\left(\mathrm{m}^{3} \mathrm{~m}^{-3} \mathrm{~d}^{-1}\right)$ & $0,89 \pm 0,22(39)$ & $1,00 \pm 0,27(39)$ & $0,89 \pm 0,34(39)$ \\
\hline \multirow{3}{*}{$\|$} & TDH (d) & $1,54 \pm 0,35(34)$ & $1,03 \pm 0,17(34)$ & $1,58 \pm 0,51(34)$ \\
\hline & $\operatorname{COV}\left(\mathrm{kg} \mathrm{m}^{-3} \mathrm{~d}^{-1}\right)$ & $1,57 \pm 0,24(13)$ & $2,40 \pm 0,71(13)$ & $1,67 \pm 0,57(13)$ \\
\hline & $\mathrm{CHV}\left(\mathrm{m}^{3} \mathrm{~m}^{-3} \mathrm{~d}^{-1}\right)$ & $0,69 \pm 0,18(34)$ & $1,00 \pm 0,19(34)$ & $0,71 \pm 0,26(34)$ \\
\hline \multirow{3}{*}{ III } & TDH (d) & $1,54 \pm 0,39(30)$ & $1,06 \pm 0,33(30)$ & $1,51 \pm 0,41(30)$ \\
\hline & $\operatorname{COV}\left(\mathrm{kg} \mathrm{m}^{-3} \mathrm{~d}^{-1}\right)$ & $3,17 \pm 0,95(16)$ & $4,41 \pm 1,11(16)$ & $3,35 \pm 1,23(16)$ \\
\hline & $\mathrm{CHV}\left(\mathrm{m}^{3} \mathrm{~m}^{-3} \mathrm{~d}^{-1}\right)$ & $0,69 \pm 0,18(30)$ & $1,02 \pm 0,28(30)$ & $0,72 \pm 0,23(30)$ \\
\hline
\end{tabular}

(a) Em parênteses, o número de amostragens considerado no cálculo da média; R1 - escória; R2 - espuma; e R3 - brita

Após este período as concentrações de DQO e de compostos fenólicos aplicadas nos reatores foram aumentadas gradativamente mantendo-se o TDH em torno de 1,3 dias, o que resultou em três fases de operação com duração de 40, 41 e 38 dias, respectivamente. Nas fases I (partida) e II, os reatores foram alimentados com água residuária do processamento dos frutos do cafeeiro (ARC) diluída com água da rede pública de abastecimento; na terceira fase (Fase III), utilizou-se a água residuária bruta.

Durante o período experimental a ARC utilizada na alimentação dos reatores teve o pH corrigido. No início, utilizou-se calcário calcítico, na proporção de $0,42 \mathrm{~g}$ de $\mathrm{CaCO}_{3}$ adicionado por g de DQO. Devido à baixa solubilidade do calcário em água passou-se, a partir do $13^{\circ}$ dia de operação, a utilizar o carbonato de sódio, na proporção de $0,18 \mathrm{~g}$ de $\mathrm{Na}_{2} \mathrm{CO}_{3}$ adicionado por $\mathrm{g}$ de DQO, que se estendeu até o final do experimento.

Os reatores foram operados a temperatura ambiente que variou de $6,4^{\circ} \mathrm{C}$ (mínima) a $32,9^{\circ} \mathrm{C}$ (máxima), com valor médio de $17,2^{\circ} \mathrm{C}$ durante o período avaliado.

As condições operacionais aplicadas durante o período experimental tais como tempo de detenção hidráulica (TDH), carga orgânica volumétrica (COV) e carga hidráulica volumétrica (CHV), podem ser visualizadas na Tabela 3 .

Fez-se o monitoramento dos reatores por amostras do afluente e do efluente, quantificando-se as variáveis alcalinidade bicarbonato $(\mathrm{AB})$ e ácidos voláteis totais (AVT), tal como descrito por Ripley et al. (1986), e DQO, pelo método do refluxo aberto (APHA, 2005). Os fenóis totais foram quantificados pelo método colorimétrico, com o uso do reagente FolinDenis, sendo que o ácido tânico foi utilizado para construção da curva padrão (Folin \& Denis, 1912). As variáveis acima citadas foram analisadas com frequência de 2 a 3 vezes por semana, sendo que os valores de $\mathrm{pH}$ foram obtidos diariamente.

Obtiveram-se os parâmetros cinéticos após o monitoramento das concentrações de compostos fenólicos, ao longo da 
altura dos reatores. Esses perfis foram obtidos em 18 amostragens ( 2 para cada fase operacional dos 3 reatores), e as amostras foram coletadas em sete pontos do reator correspondendo à entrada, zona com material suporte ( 5 coletas) e saída.

\section{RESULTADOS E DISCUSSÃO}

\section{Desempenho dos reatores}

Na Tabela 4 se acham os valores de DQO, compostos fenólicos, AB, AVT e pH no afluente e efluente dos reatores, durante as três fases de operação do sistema. As eficiências médias de remoção das variáveis monitoradas em cada fase operacional, estão apresentadas na Tabela 5.

Durante o período experimental se aumentou, gradualmente, a carga orgânica aplicada aos reatores mantendo-se o TDH constante; entretanto, em decorrência da grande oscilação observada na vazão afluente não foi possível manter as condições operacionais, tais como COV, CHV e TDH, iguais nos três reatores (Tabela 3).

Variações na vazão, aliadas às flutuações na temperatura ambiente, provocaram grandes oscilações na estabilidade do sistema. Desta forma, não se obtiveram efluentes com concentrações de compostos fenólicos estáveis (Figura 1), nem eficiências de remoção (Figura 2), durante as três fases experimentais.

Durante a primeira fase, na qual os reatores foram alimentados com concentração média de matéria orgânica em termos de DQO, de $978 \mathrm{mg} \mathrm{L}^{-1}$, e concentração média de compostos fenólicos de $13 \mathrm{mg} \mathrm{L}^{-1}$, semelhantes remoções de DQO foram obtidas nos reatores R1 e R3, porém inferiores às do R2.

Com relação aos compostos fenólicos, as eficiências de remoção obtidas nos reatores estão associadas, possivelmente, à degradação anaeróbia dessas substâncias, porém a maior eficiência de remoção apresentada no R1 (68\%) teve, como diferencial, a possibilidade de adsorção de compostos fenólicos na escória, já que a escória possui cargas elétricas superficiais e os fenóis são compostos polares. Conforme rela- tado por Adak \& Pal (2006), a alumina $\left(\mathrm{Al}_{2} \mathrm{O}_{3}\right)$ contida neste material apresenta potencial de adsorção de fenóis.

Pela análise dos resultados obtidos em todo o período experimental, verificou-se que as menores eficiências de remoção de DQO e compostos fenólicos, ocorreram na Fase I ( $7^{\circ}$ dia de operação), no reator R3, sendo os valores obtidos de 9,3 e -61\%; esta perda de eficiência foi causada por variações repentinas de carga hidráulica e por baixas temperaturas observadas no período o que causou lavagem da biomassa. Tais fatos demonstram a sensibilidade do R3 sob as condições operacionais impostas durante o período de "partida" do reator. O valor negativo de eficiência de remoção de compostos fenólicos refere-se a uma amostra pontual em que a concentração no efluente de R3 foi maior que a concentração no afluente do mesmo.

A segunda fase, caracterizada pelo aumento da concentração de matéria orgânica e de compostos fenólicos para 2.401 $\mathrm{mg} \mathrm{L}^{-1}$ e $19,7 \mathrm{mg} \mathrm{L}^{-1}$, respectivamente, foi marcada por incrementos na remoção de DQO. Observa-se, nas Tabelas 3 e 5, que o R2, mesmo tendo sido submetido a maior COV $(2,4 \mathrm{~kg}$ $\left.\mathrm{m}^{-3} \mathrm{~d}^{-1}\right)$ e menor TDH (1,03 dias), alcançou eficiência média de 73\%. Bello-Mendoza \& Castillo-Rivera (1998), tratando águas residuárias do processamento dos frutos do cafeeiro em um sistema composto por reator UASB seguido de filtro anaeróbio, em escala piloto, submetido a um TDH de 0,92 d e COV de $1,89 \mathrm{~kg} \mathrm{~m}^{-3} \mathrm{~d}^{-1}$ de DQO, obtiveram eficiência de remoção de $77 \%$ de DQO total e constataram que $1,9 \mathrm{~kg} \mathrm{~m}^{-3} \mathrm{~d}^{-1}$

Tabela 5. Eficiência (\%) média de remoção DQO e compostos fenólicos pelos reatores, durante as três fases de operação do sistema

\begin{tabular}{ccccc}
\hline \multicolumn{2}{c}{ Fases/Pontos } & R1 & R2 & R3 \\
\multirow{2}{*}{1} & DQO & $47 \pm 19$ & $58 \pm 14$ & $42 \pm 17$ \\
& FenolT & $68 \pm 20$ & $52 \pm 11$ & $36 \pm 35$ \\
\hline \multirow{2}{*}{2} & DQO & $61 \pm 17$ & $73 \pm 8$ & $54 \pm 16$ \\
& FenolT & $67 \pm 23$ & $44 \pm 10$ & $36 \pm 14$ \\
\hline \multirow{2}{*}{3} & DQO & $64 \pm 18$ & $80 \pm 15$ & $72 \pm 19$ \\
& FenolT & $62 \pm 13$ & $46 \pm 15$ & $44 \pm 16$ \\
\hline
\end{tabular}

R1 - escória; R2 - espuma; e R3 - brita

Tabela 4. Valores médios das variáveis de monitoramento afluente e efluente dos reatores, em cada fase operacional

\begin{tabular}{|c|c|c|c|c|c|c|}
\hline \multirow{2}{*}{\multicolumn{2}{|c|}{ Fases/pontos }} & DQO & FenolT & $\overline{A B}$ & $\overline{A V T}$ & $\mathrm{pH}$ \\
\hline & & \multicolumn{4}{|c|}{$\mathrm{mg} \mathrm{L}^{-1}$} & \\
\hline \multirow{4}{*}{1} & Af & $978 \pm 113(16)$ & $13,0 \pm 3,8(10)$ & $74 \pm 63(18)$ & $300 \pm 88(18)$ & $6,44 \pm 0,59(31)$ \\
\hline & R1 & $514 \pm 184(15)$ & $4,2 \pm 2,6(10)$ & $253 \pm 121(17)$ & $242 \pm 89(17)$ & $7,53 \pm 0,26(30)$ \\
\hline & $\mathrm{R} 2$ & $415 \pm 135(15)$ & $6,3 \pm 1,4(10)$ & $203 \pm 102(17)$ & $160 \pm 82(17)$ & $6,85 \pm 0,32(30)$ \\
\hline & R3 & $572 \pm 165(15)$ & $8,3 \pm 4,6(10)$ & $160 \pm 110(17)$ & $215 \pm 80(17)$ & $6,81 \pm 0,37(30)$ \\
\hline \multirow{4}{*}{2} & Af & $2.401 \pm 597(13)$ & $19,7 \pm 4,2(12)$ & $199 \pm 165(12)$ & $969 \pm 177(12)$ & $6,55 \pm 0,46(22)$ \\
\hline & R1 & $935 \pm 417(13)$ & $6,5 \pm 4,5(12)$ & $651 \pm 272(12)$ & $625 \pm 160(12)$ & $7,56 \pm 0,33(22)$ \\
\hline & $\mathrm{R} 2$ & $649 \pm 189(13)$ & $11,0 \pm 2,0(12)$ & $625 \pm 234(12)$ & $406 \pm 95(12)$ & $7,20 \pm 0,23(22)$ \\
\hline & R3 & $1.095 \pm 373(13)$ & $12,6 \pm 2,7(12)$ & $516 \pm 196(12)$ & $578 \pm 195(12)$ & $7,16 \pm 0,28(22)$ \\
\hline \multirow{4}{*}{3} & Af & $4.545 \pm 511(16)$ & $42,7 \pm 5,3(16)$ & $575 \pm 98(16)$ & $2.021 \pm 360(16)$ & $7,06 \pm 0,14(21)$ \\
\hline & R1 & $1.627 \pm 838(16)$ & $16,1 \pm 5,4(16)$ & $1.553 \pm 406(16)$ & $1.083 \pm 481(16)$ & $7,92 \pm 0,20(21)$ \\
\hline & $\mathrm{R} 2$ & $932 \pm 668(16)$ & $23,0 \pm 6,2(16)$ & $1.638 \pm 320(16)$ & $763 \pm 359(16)$ & $7,67 \pm 0,16(21)$ \\
\hline & R3 & $1.261 \pm 884(16)$ & $24,0 \pm 6,9(16)$ & $1.508 \pm 338(16)$ & $897 \pm 458(16)$ & $7,72 \pm 0,21(21)$ \\
\hline
\end{tabular}

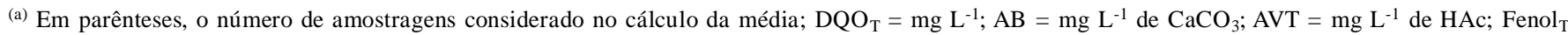
= mg L L ${ }^{-1}$ de Ác. Tânico; Af - Afluente; R1 - escória; R2 - espuma e; R3 - brita 


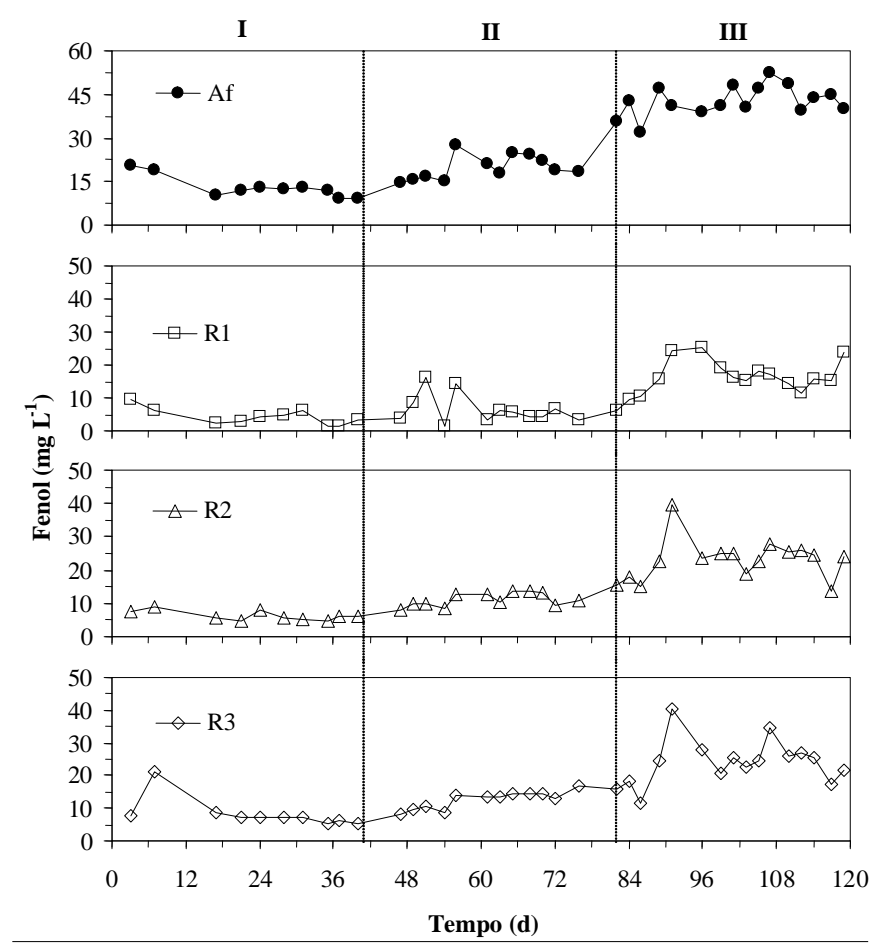

Figura 1. Variação das concentrações de compostos fenólicos afluente e efluente dos reatores avaliados em cada fase operacional (R1 - escória; R2 - espuma; e R3 - brita)

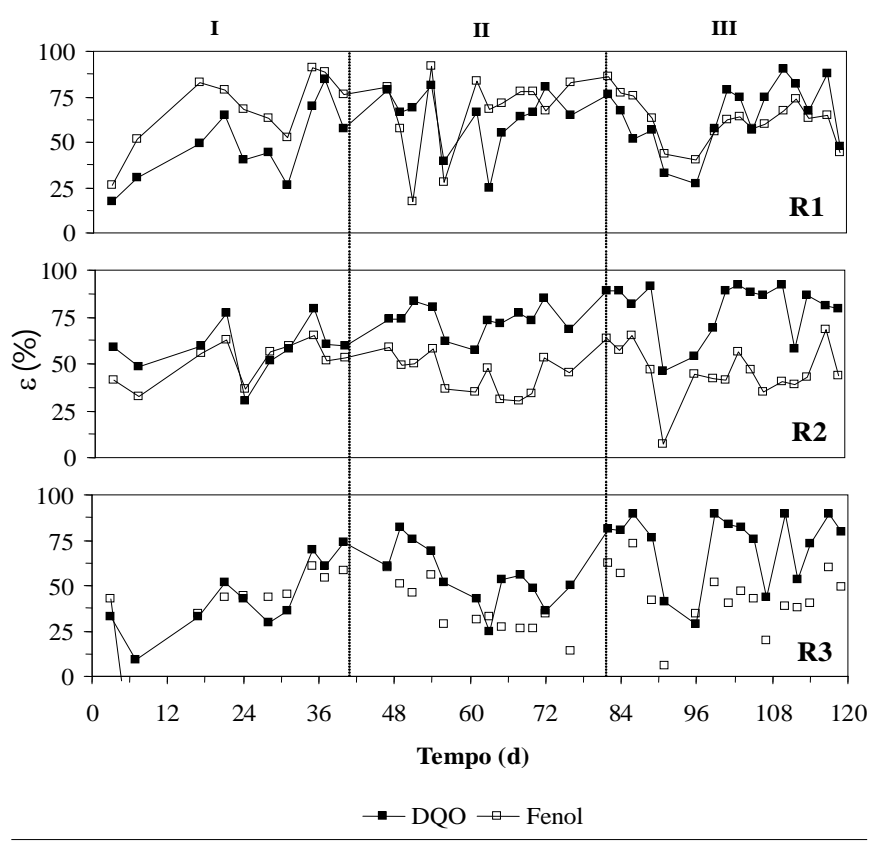

Figura 2. Variação na eficiência de remoção de DQ 0 e compostos fenólicos nos reatores avaliados em cada fase operacional (R1 - escória; R2 - espuma; e R3 brita)

de DQO foi a máxima COV aplicada sem desestabilização do processo.

Pequena redução na eficiência média na remoção dos compostos fenólicos foi observada em R1 e R2, enquanto em R3 permaneceu praticamente constante; apesar disso, o reator R1 foi capaz de atingir máxima eficiência de remoção de $92 \%$, no $54^{\circ}$ dia de operação.
A Fase III compreendeu o período de máxima aplicação de carga orgânica e, consequentemente, de compostos fenólicos. Devido ao aumento da concentração de DQO aplicada aos reatores $\left(4.545 \mathrm{mg} \mathrm{L}^{-1}\right)$, juntamente com a redução da temperatura ambiente observada neste período notou-se, no início desta fase, desestabilização do processo com perda de eficiência dos reatores; verificou-se, entretanto, que os reatores foram capazes de amortecer essa alteração de COV promovendo incrementos na eficiência média de remoção de DQO (Tabela 5).

A máxima eficiência de remoção de matéria orgânica (92\%) foi atingida nessa fase pelo reator R2, quando operado com COV e TDH de 4,41 $\mathrm{kg} \mathrm{m}^{-3} \mathrm{~d}^{-1}$ e 1,06 dias, respectivamente. Deste modo constatou-se que, nas três fases de tratamento, o R2 se mostrou mais resistente às alterações de carga orgânica e hidráulica, o que resultou em maior estabilidade operacional do sistema e em maior remoção, em valores médios de DQO, além das menores concentrações efluentes de ácidos voláteis totais e maiores de alcalinidade bicarbonato.

A mudança na concentração de compostos fenólicos afluente para 42,7 mg L-1, na Fase III, coincidiu com decréscimo na eficiência de R1; entretanto, R2 e R3 mostraram tendência de aumento na eficiência de remoção deste composto orgânico. A perda de eficiência em R1 foi resultado das variações de CHV que, provavelmente, conduziu ao desprendimento de partículas de escória junto com o biofilme aderido, em virtude da grande fragilidade estrutural deste material suporte. Acredita-se, também, que os maiores valores de $\mathrm{pH}$ constatados no efluente deste reator, quando comparado com o observado ao dos demais, possam ter influenciado na adsorção de compostos fenólicos pela escória em razão do aumento de cargas negativas pH-dependentes. Estudos conduzidos por Adak \& Pal (2006) e Xiaoli \& Youcai (2006) mostraram que a remoção de fenol diminuiu com o aumento no valor do $\mathrm{pH}$. Para baixos valores de $\mathrm{pH}$ (muito menor que $\mathrm{pKa}$ ), compostos fenólicos são adsorvidos em sua forma molecular $\left(\mathrm{C}_{6} \mathrm{H}_{5} \mathrm{OH}\right)$ porém, quando o valor de $\mathrm{pH}$ aumenta (maior que $\mathrm{pKa})$, a fração aniônica do fenol $\left(\mathrm{C}_{6} \mathrm{H}_{5} \mathrm{O}^{-}\right)$predomina.

Sabe-se também que, em geral, as bactérias apresentam cargas negativas em sua superfície (Ortega et al., 2001), de modo que o predomínio da fração aniônica do fenol (observado em maiores valores de $\mathrm{pH}$ ) pode ter-se tornado uma barreira físico-química, por repulsão ao fenol o que, provavelmente, resultou em redução na adsorção deste composto orgânico pela escória. No reator R3, apesar de terem sido observadas as menores eficiências de remoção desses compostos, verificaram-se incrementos na eficiência de remoção com o aumento na concentração de compostos fenólicos aplicada, o que pode se um indicativo de maior adaptação dos microrganismos às condições de toxicidade proporcionada por esta substância.

Bruno \& Oliveira (2008), tratando ARC por meio de reatores UASB em dois estágios, obtiveram eficiências médias de remoção de compostos fenólicos variando de 72 e $90 \%$ para concentrações afluentes entre 79,7 e $97,4 \mathrm{mg} \mathrm{L}^{-1}$, sendo que as maiores eficiências foram obtidas quando o $\mathrm{TDH}$ foi de 6,17 dias. Comparando-se os resultados do presente trabalho 
com os obtidos por este autor, verifica-se pior desempenho dos reatores operados neste trabalho, provavelmente em razão de terem sido submetidos a menores TDHs e serem montados e conduzidos em ambiente aberto influenciado pelas variações bruscas de temperatura; por outro lado, o fato do autor ter utilizado reatores em série pode ter favorecido o aumento da eficiência global do sistema.

Apesar de ser relatada, na literatura, a toxicidade de compostos fenólicos aos microrganismos, Fang et al. (1996) obtiveram, tratando águas residuárias com concentrações de fenóis totais de $1.260 \mathrm{mg} \mathrm{L}^{-1}$, eficiência de remoção de $97 \%$, em um sistema composto por reator UASB operando com TDH de $12 \mathrm{~h}$ a $37^{\circ} \mathrm{C}$ de temperatura. Fang et al. (2006) verificaram $99 \%$ de redução na concentração inicial de fenol $\left(630 \mathrm{mg} \mathrm{L}^{-}\right.$ ${ }^{1}$ ), com o uso de um reator UASB; entretanto, os autores operaram o sistema em condições termofílicas $\left(55^{\circ} \mathrm{C}\right)$ e com TDH de 1,7 dias.

Fountoulakis et al. (2002) observaram a remoção de $78 \%$ dos compostos fenólicos presentes em águas residuárias do processamento do óleo de oliva com concentração inicial de $4.050 \mathrm{mg} \mathrm{L}^{-1}$, utilizando fungos (Pleurotus ostreatus) e TDH de 21 dias; já Fezzani \& Cheikh (2007) investigando a codigestão anaeróbia termofílica $\left(55^{\circ} \mathrm{C}\right)$ de águas residuárias do processamento do óleo de oliva, obtiveram eficiência de remoção de fenóis totais de $72 \%$, para uma concentração inicial de $13.000 \mathrm{mg} \mathrm{L}^{-1}$ e TDH de 36 dias.

$\mathrm{Na}$ literatura se encontram maiores eficiências de remoção de matéria orgânica e compostos fenólicos de águas residuárias tratadas por processos anaeróbios quando comparadas com as eficiências encontradas neste trabalho; no entanto, vários são os processos empregados o que dificulta, sobre- maneira, a comparação dos dados. A condução experimental também influencia a eficiência dos sistemas tais como TDH, temperatura, $\mathrm{pH}$, carga orgânica e hidráulica e concentração afluente. Neste trabalho, por exemplo, verificou-se forte influência das variações de temperatura e CHV. Vale ressaltar também, que as características intrínsecas das águas residuárias podem favorecer ou dificultar o tratamento. Águas fenólicas de origem agroindustrial apresentam moléculas diferentes daquelas de origem industrial, o que influencia na degradação desses compostos.

Assim, as eficiências médias de remoção de DQO e compostos fenólicos obtidas neste trabalho, podem ser consideradas satisfatórias tendo em vista as condições operacionais às quais os reatores foram expostos.

\section{Estudo cinético da degradação de compostos fenólicos}

Os parâmetros cinéticos apresentados na Tabela 6 foram obtidos do perfil da concentração de compostos fenólicos ao longo da altura dos reatores, por meio dos métodos descritos por Bhunia \& Ghangrekar (2008). Várias tentativas foram feitas a fim de se ajustar diferentes modelos cinéticos (ordem zero, primeiro ordem, segunda ordem, Monod e Haldane) aos resultados experimentais, mas os modelos de Monod e Haldane foram os que melhor representaram o comportamento cinético dos reatores anaeróbios de leito fixo nas três fases de operação devido aos maiores valores de $\mathrm{R}^{2}$ obtidos com a aplicação desses modelos.

Observou-se que o aumento na concentração de compostos fenólicos para 19,7 (Fase II) levou a uma redução nos valores de $\mu_{\text {máx }}$ obtidos para R1 e R3, tanto para o modelo de Monod quanto para Haldane, o que pode ser considerado uma indicação indireta para inibição de crescimento para tais con-

Tabela 6. Valores dos coeficientes cinéticos ajustados $\left(K_{S}\right.$ - constante de saturação; $K_{i}$ - constante de inibição; $\mu_{\operatorname{máx}}$ - taxa de crescimento específico máxima e $k_{\text {máx }}$ - taxa máxima de conversão do substrato)

\begin{tabular}{|c|c|c|c|c|c|c|c|c|c|c|}
\hline \multirow{2}{*}{\multicolumn{2}{|c|}{ Modelos Cinéticos }} & \multicolumn{3}{|c|}{ R1 } & \multicolumn{3}{|c|}{ R2 } & \multicolumn{3}{|c|}{ R3 } \\
\hline & & 1 & 2 & 3 & 1 & 2 & 3 & 1 & 2 & 3 \\
\hline \multirow{4}{*}{ Monod } & $\mathrm{KS}$ & 4,8787 & 2,7292 & 34,8028 & 7,1666 & 1,2548 & 26,7024 & 5,8508 & 15,6808 & 11,4123 \\
\hline & máx & 0,0174 & 0,0029 & 0,8542 & 0,0561 & 13,0885 & 16,0751 & 0,0088 & 0,0005 & 0,3610 \\
\hline & kmáx & 0,0732 & 0,0033 & 0,0730 & 0,0036 & 0,1283 & 0,8857 & 0,0094 & 0,0019 & 0,0775 \\
\hline & $\mathrm{R} 2$ & 0,2413 & 0,8547 & 0,5242 & 0,8623 & 0,6427 & 0,8153 & 0,9466 & 0,9370 & 0,2786 \\
\hline \multirow{5}{*}{ Haldane } & $\mathrm{KS}$ & 1,5351 & 1,4557 & 10,1762 & 3,8639 & 5,3863 & 5,4615 & 3,6158 & 24,3199 & 10,6327 \\
\hline & $\mathrm{Ki}$ & 4,8710 & 5,8138 & 39,6650 & 15,0067 & 29,2559 & 57,1598 & 13,7094 & 27,1330 & 41,8957 \\
\hline & máx & 0,0030 & 0,0003 & 0,0158 & 0,0156 & 1,5402 & 2,6297 & 0,0043 & 0,0008 & 0,0072 \\
\hline & kmáx & 0,0128 & 0,0003 & 0,0013 & 0,0010 & 0,0151 & 0,1449 & 0,0046 & 0,0034 & 0,0015 \\
\hline & $\mathrm{R} 2$ & 0,4119 & 0,9998 & 0,7386 & 0,9373 & 0,7290 & 0,8556 & 0,9691 & 0,9385 & 0,8077 \\
\hline
\end{tabular}

$\mathrm{K}_{\mathrm{S}}=\mathrm{mg} \mathrm{L}^{-1} ; \mathrm{K}_{\mathrm{i}}=\mathrm{mg} \mathrm{L}^{-1}, \mu_{\text {máx }}=\mathrm{d}^{-1} ; \mathrm{k}_{\text {máx }}=\mathrm{d}^{-1} ; \mathrm{R} 1$ - escória; R2 - espuma e; R3 - brita

Tabela 7. Coeficientes cinéticos de biodegradação de fenol obtidos pelos modelos de Monod e Haldane

\begin{tabular}{cccccccc}
\hline \multirow{2}{*}{ Modelos } & Reator/Culturas & $\mathbf{C}_{0}$ & \multicolumn{4}{c}{ Parâmetros Cinéticos } & Referências \\
\cline { 5 - 7 } Monod & Leito fluidizado Pseudomonas putida & 1000 & $\mathbf{K}_{\mathbf{s}}$ & $\boldsymbol{\mu}_{\text {máx }}$ & $\mathbf{k}_{\text {máx }}$ & $\mathbf{K}_{\mathbf{i}}$ & González et al. (2001) \\
& Batelada Bacillus brevis & $750-1750$ & $2,88-82,45$ & $0,504-1,464$ & $0,883-4,996$ & - & Arutchelvan et al. (2006) \\
& Batelada Acinetobacter calcoaceticus & $60-500$ & 30,96 & 14,11 & - & - & Kumaran \& Paruchuri (1997) \\
\hline \multirow{4}{*}{ Halnade } & Batelada Bacillus brevis & $750-1750$ & $2,20-29,31$ & $0,624-1,872$ & $1,093-6,389$ & $868-2435$ & Arutchelvan et al. (2006) \\
& Aspergillus awamori & $300-1000$ & $916-1013$ & $0,406-5,587$ & $0,811-1,414$ & $1023-1088$ & Stoilova et al. (2006) \\
& Bioreator de membrana Mixed culture & $500-3000$ & 29,54 & 0,438 & - & 72,45 & Marrot et al. (2006) \\
& Batelada Acinetobacter calcoaceticus & $60-500$ & 36,2 & 13,01 & - & 145 & Kumaran \& Paruchuri (1997) \\
\hline
\end{tabular}


centrações de fenol aplicadas, o que foi confirmado pelo baixo valor de $\mathrm{K}_{\mathrm{i}}$ apresentado por R1; já R2 não apresentou efeito inibitório no crescimento para as concentrações de fenol aplicadas (Tabela 6).

Pela análise das cinéticas de crescimento aplicadas, tornase evidente que a representada pelo modelo de Haldane foi mais satisfatória que o modelo de Monod, devido aos maiores valores de $\mathrm{R}^{2}$ apresentados. De acordo com Marrot et al. (2006) e considerando que o fenol é um substrato inibitório para a maioria das espécies, a equação de Haldane tem sido frequentemente usada para modelar a degradação de fenol e, comparada à equação de Monod, promove uma representação melhor dos dados observados. Este modelo descreve relativamente bem o crescimento microbiano na presença de um substrato que é, ao mesmo tempo, um inibidor do metabolismo da população microbiana. Até mesmo em baixas concentrações o fenol apresenta efeito inibitório significativo na taxa de crescimento específica $(\mu)$.

Na Tabela 7 apresenta-se o resumo de coeficientes cinéticos obtidos na literatura relacionados com a degradação de fenólicos utilizando-se microrganismos adaptados.

Verifica-se que os coeficientes cinéticos obtidos no presente trabalho foram menores que os citados na literatura; este fato indica menor capacidade de degradação e uma cinética mais lenta devido, provavelmente, às baixas concentrações de compostos fenólicos aplicadas nos reatores.

\section{CONCLUSÕES}

1. Os reatores anaeróbios de leito fixo, preenchidos com diferentes materiais suporte, mostraram-se satisfatórios no tratamento das águas residuárias do processamento dos frutos do cafeeiro.

2. A rápida aclimatação da biomassa aderida à escória de alto forno resultou em maiores eficiências de remoção de compostos fenólicos durante todo o período experimental, sendo que a máxima eficiência de remoção (92\%) foi alcançada quando se utilizou concentração afluente de $19,7 \mathrm{mg} \mathrm{L}^{-1}$ de compostos fenólicos e TDH de 1,54 dias.

3. Os compostos fenólicos exibiram efeito inibitório para R1 e R3 sendo que a cinética de crescimento foi bem descrita pelo modelo de Haldane.

4. Os resultados indicaram maior potencialidade de aplicação da escória de alto-forno como material suporte de reatores anaeróbios para remoção de compostos fenólicos da ARC.

\section{LITERATURA CITADA}

Adak, A.; Pal, A. Removal of phenol from aquatic environment by SDS-modified alumina: Batch and fixed bed studies. Separation and Purification Technology, v.50, p.256-262, 2006.

APHA; AWWA; WEF. Standard methods for examination of water and wastewater. 21.ed. Washington: APHA/AWWA/WEF, 2005. 1268p.

Arutchelvan, V.; Kanakasabai, V.; Elangovan, R.; Nagarajan, S.; Muralikrishnan, V. Kinetics of high strength phenol degradation using Bacillus brevis. Journal of Hazardous Materials, B129, p.216-222, 2006.
Bae, B.; Autenrieth, R. L.; Bonner, J. S. Kinetics of multiple phenolic compounds degradation with a mixed culture in a continuous-flow reactor. Water Environment Research, v.67, p.215-223, 1995.

Bello-Mendoza, R.; Castillo-Rivera, M. F. Start-up of an anaerobic hybrid UASB/filter reactor treating wastewater from a coffee processing plant. Anaerobe, v.4, p.219-225, 1998.

Bhunia, P.; Ghangrekar M. M. Analysis, evaluation, and optimization of kinetic parameters for performance appraisal and design of UASB reactors. Bioresource Technology, v.99, p.21322140, 2008.

Bolaños, M. L. R.; Varesche, M. B. A.; Zaiat, M.; Foresti, E. Phenol degradation in horizontal-flow anaerobic immobilized biomass (HAIB) reactor under mesophilic conditions. Water Science and Technology, v.44, n.4, p.167-174, 2001.

Brasil. Conselho Nacional do Meio Ambiente (CONAMA), Resolução $\mathrm{n}^{\circ} 357,17 / 03 / 05$. Dispõe sobre a classificação dos corpos de águas e diretrizes ambientais para o seu enquadramento, bem como estabelece as condições e padrões de lançamento de efluentes, e dá outras providências. Brasília: CONAMA, 2005. 23p.

Bruno, M.; Oliveira, R. A. de. Tratamento anaeróbio de águas residuárias do beneficiamento de café por via úmida em reatores UASB em dois estágios. Engenharia Agrícola, v.28, n.2, p.364-377, 2008.

Fang, H. H. P.; Chui, H.; Li, Y.; Chen, T. Degradation of phenol in an up flow anaerobic sludge blanket reactor. Water Research, v.30, n.6, p.1356-1360, 1996.

Fang, H. H. P.; Liang, D. W.; Zhang, T.; Liu, Y. Anaerobic treatment of phenol in wastewater under thermophilic condition. Water Research, v.40, p.427-434, 2006.

Fang, H. H. P.; Liu, Y.; Ke, S. Z.; Zhang, T. Anaerobic degradation of phenol in wastewater at ambient temperature. Water Science Technology, v.49, p.95-102, 2004.

Fezzani, B.; Cheikh, R. B. Thermophilic anaerobic co-digestion of olive mill wastewater with olive mill solid wastes in a tubular digester. Chemical Engineering Journal, v.132, p.195203, 2007.

Folin, O.; Denis, W. On phosphotungstic-phosphomolybdic compounds as color reagents. The Journal of Biological Chemistry, v.12, n.2, p.239-243, 1912.

Fountoulakis, M. S.; Dokianakis, S. N.; Kornaros, M. E.; Aggelis, G. G.; Lyberatos, G. Removal of phenolics in olive mill wastewaters using the white-rot fungus Pleurotus ostreatus. Water Research, v.36, p.4735-4744, 2002.

González, G.; Herrera, G.; García, M. T.; Pena, M. Biodegradation of phenolic industrial wastewater in a fluidized bed bioreactor with immobilized cells of Pseudomonas putida. Bioresource Technology, v.80, p.137-142, 2001.

Jiang, M. H. L; Tay, J. H; Tay, S. T. L. Aggregation of immobilized activated sludge cells into aerobically grown microbial granules for the aerobic biodegradation of phenol. Letters in Applied Microbiology, v.35, p.439-445, 2002.

Khleifat, K. M. Biodegradation of phenol by Ewingella america$n a$ : Effect of carbon starvation and some growth conditions. Process Biochemistry, v.41, n.9, p.2010-2016, 2006. 
Kumaran, P.; Paruchuri, Y. L. Kinetics of phenol biotransformation. Water Research, v.31, n.1, p.11-22, 1997.

Luiz, F. A. R.; Campos, C. M. M.; Carmo, A. C. Partida de um reator UASB em escala laboratorial tratando efluente líquido proveniente do despolpamento do café. In: Congresso Brasileiro de Engenharia Agrícola, 23, 2004, São Pedro. Anais... São Pedro: SBEA, 2004. CD-Rom.

Marrot, B.; Barrios-Martinez, A.; Moulin, P.; Roche, N. Biodegradation of high phenol concentration by activated sludge in na immersed membrane bioreactor. Biochemical Engineering Journal, v.30, p.174-183, 2006.

Monod, J. La technique de culture continue: Theorie and applications. Annales de l'Institut Pasteur, n.79, p.390-410, 1950.

Ortega, F. S.; Rocha, K. M.; Zaiat, M.; Pandolfelli, V. C. Aplicação de espumas cerâmicas produzidas via "gelcasting" em biorreator para tratamento anaeróbio de águas residuárias. Cerâmica, v.47, n.304, p.199-203, 2001.

Ripley, L. E.; Boyle, W. C.; Converse, J. C. Improved alkalimetric monitoring anaerobic digestion of high-strenght wastes. Journal of Water Pollution Control Federation, v.58, p.406-411, 1986.
Sarkar, M.; Acharya, P. K. Use of fly ash for the removal of phenol and its analogues from contaminated water. Waste Management, v.26, p.559-570, 2006.

Stoilova, I.; Krastanov, A.; Stanchev, V.; Daniel, D.; Gerginova, M.; Alexieva, Z. Biodegradation of high amounts of phenol, catechol, 2,4-dichlorophenol and 2,6-dimethoxyphenol by Aspergillus awamori cells. Enzyme and Microbial Technology, v.39, p.1036-1041, 2006.

Tello, E. Optimización de tecnologías fotocatalíticas de oxidación avanzadas al tratamiento de residuos líquidos del laboratorio. Las Palmas de Gran Canaria: University of Las Palmas de Gran Canaria, 2001. Ph.D. Dissertation

Veeresh, G. S.; Kumar, P.; Mehrotra, I. Treatment of phenol and cresols in upflow anaerobic sludge blanket (UASB) process: A review. Water Research, v.39, p.154-170, 2005.

Xiaoli C.; Youcai, Z. Adsorption of phenolic compound by agedrefuse. Journal of Hazardous Materials, v.137, p.410-417, 2006.

Zaiat, M.; Cabral, A. K. A.; Foresti, E. Horizontal-flow anaerobic immobilized sludge reactor for wastewater treatment: Conception and performance evaluation. Revista Brasileira de Engenharia, Caderno de Engenharia Química, v.11, p.33-42, 1994. 